\section{Is High Leukocyte Count Synonymous With the Presence of Endothelial Dysfunction or Atherosclerosis?}

\section{To the Editor:}

I read with interest the article entitled "High Leukocyte Count Is Associated With Peripheral Vascular Dysfunction in Individuals With Low Cardiovascular Risk" by Li et al $^{1}$ in a recent issue of the Journal. The authors concluded that a relatively high leukocyte count is independently associated with vascular dysfunction in persons at low cardiovascular (CV) risk. They also suggested that the leukocyte count may be a useful tool for $\mathrm{CV}$ screening in persons at low $\mathrm{CV}$ risk. I have some comments about this study.

Blood flow in the finger may be altered by some factors such as changes in room temperature, mental stress and other alterations in vascular tone. ${ }^{2}$ I wonder about the reason for using $\leq 1.67$ as a cut-off point for endothelial dysfunction and the authors' cut-off point. It has been suggested that the maximal increase in diameter occurs $>60$ s after cuff release and the relation between cardiovascular risk factors and peripheral arterial tonometry (PAT) hyperemic response is strongest in the 90-120-s interval after fingertip flow is restored. ${ }^{3}$ Indeed, some studies have demonstrated a negative effect of endothelial dysfunction on outcome in patients with documented coronary artery disease. ${ }^{4}$ Although the authors stated that all vasoactive drugs were discontinued at least $24 \mathrm{~h}$ prior to testing, some of these drugs with longer half-lives may have had an effect on the PAT measurement. An another important caveat is that the number of menopausal women $(n=136)$ is larger than the total number of patients $(n=105)$ in Table 1 . There may be also a possible influence of the menstrual cycle.

Additionally, detection of neutrophils in human atherosclerotic plaque is very diffucult because of their limited life span. ${ }^{5}$ At this point, the question waiting for an answer is: Does only the neutrophil count by itself prove causality or can it be used as a surrogate marker in the treatment of atherosclerosis? If neutrophils prove to have prognostic utility independent of traditional risk factors and other subtypes of leukocytes, it would be of interest if studies of antiinflammatory drugs for atherosclerosis include neutrophil counts at baseline and in response to therapies.

The neutrophil/lymphocyte ratio (NLR) has recently emerged as a potential new biomarker for predicting future vascular events in patients with atherosclerosis. ${ }^{6}$ The results of the study in question would be stronger if the authors had used this ratio in their study population.

Perhaps more importantly, beyond being a cause, a high neutrophil count can be a result of atherosclerotic burden.

\section{Disclosures}

Conflict of interest: None

\section{References}

1. Li J, Flammer AJ, Reriani MK, Matsuo Y, Gulati R, Friedman PA, et al. High leukocyte count is associated with peripheral vascular dysfunction individulas with low cardiovascular risk. Circ J 2013; 77: 780-785.

2. Kuvin JT, Patel AR, Sliney KA, Pandian NG, Sheffy J, Schnall RP, et al. Assessment of peripheral vascular endothelial function with finger arterial pulse wave amplitude. Am Heart J 2003; 146: $168-$ 174 .

3. Hamburg NM, Keyes MJ, Larson MG, Vasan RS, Schnabel R, Pryde MM, et al. Cross-sectional relations of digital vascular function to cardiovascular risk factors in the Framingham Heart Study. Circulation 2008; 117: 2467-2474.

4. Kitta Y, Obata JE, Nakamura T, Hirano M, Kodama Y, Fujioka D, et al. Persistent impairment of endothelial vasomotor function has a negative impact on outcome in patients with coronary artery disease. $J$ Am Coll Cardiol 2009; 53: 323-330.

5. Della Bona R, Cardillo MT, Leo M, Biasillo G, Gustapane M, Trotta $\mathrm{F}$, et al. Polymorphonuclear neutrophils and instability of the atherosclerotic plaque: A causative role? Inflamm Res 2013; 62: 537-550.

6. Arbel Y, Finkelstein A, Halkin A, Birati EY, Revivo M, Zuzut M, et al. Neutrophil/lymphocyte ratio is related to the severity of coronary artery disease and clinical outcome in patients undergoing angiography. Atherosclerosis 2012; 225: 456-460.

Yavuzer Koza, MD

Department of Cardiology, Faculty of Medicine, Ataturk University, Erzurum, Turkey

(Released online January 28, 2014) 